\title{
Absorption capacity of superabsorbent polymer in cement pastes a robustness test
}

\section{Zhao, Shengying; Jensen, Ole Mejlhede; Hasholt, Marianne Tange; Guan, Xinchun}

\section{Published in:}

Materials and Structures/Materiaux et Constructions

Link to article, DOI:

10.1617/s11527-021-01636-7

Publication date:

2021

Document Version

Peer reviewed version

Link back to DTU Orbit

Citation (APA):

Zhao, S., Jensen, O. M., Hasholt, M. T., \& Guan, X. (2021). Absorption capacity of superabsorbent polymer in cement pastes: a robustness test. Materials and Structures/Materiaux et Constructions, 54(1), [46]. https://doi.org/10.1617/s11527-021-01636-7

\section{General rights}

Copyright and moral rights for the publications made accessible in the public portal are retained by the authors and/or other copyright owners and it is a condition of accessing publications that users recognise and abide by the legal requirements associated with these rights.

- Users may download and print one copy of any publication from the public portal for the purpose of private study or research.

- You may not further distribute the material or use it for any profit-making activity or commercial gain

- You may freely distribute the URL identifying the publication in the public portal 


\title{
Absorption capacity of superabsorbent polymer in cement pastes: A robustness test
}

\author{
Shengying Zhao ${ }^{\mathrm{ab}}$, Ole Mejlhede Jensen ${ }^{\mathrm{a}}$, Marianne Tange Hasholt ${ }^{\mathrm{a}}$, Xinchun Guan ${ }^{\mathrm{b}}$ \\ ${ }^{a}$ Department of Civil Engineering, Technical University of Denmark, Kgs. Lyngby, Denmark \\ $5{ }^{b}$ Key Lab of Structures Dynamic Behavior and Control of the Ministry of Education and Key \\ Lab of Smart Prevention and Mitigation of Civil Engineering Disasters of the Ministry of \\ Industry and Information Technology, Harbin Institute of Technology, Harbin, China
}

Corresponding Author: Shengying Zhao

10 ORCID: http://orcid.org/0000-0001-8148-8455

Phone: +8618845788058

Email: 16B933033@stu.hit.edu.cn

\begin{abstract}
The aim of this study is to investigate how the absorption capacity of a superabsorbent polymer (SAP) in cement paste is influenced by a number of variables: cement type, water-to-cement ratio $(w / c)$, additive, dry SAP particle size, mixing time, and temperature. By means of air void analysis of hardened cement paste, the absorption capacity and the specific surface of SAP voids are obtained. Parallel to the direct measurement of specific surface, this parameter is also derived from dry SAP particle size and absorption capacity. The results show that for the specific type of SAP examined the largest variation in absorption capacity is observed when changing the cement type. Prolonged mixing time can increase the absorption capacity of SAP up to $20 \%$. The influence of a superplasticizer on the absorption capacity of SAP is statistically significant, whereas $w / c$ ratio or dry SAP size has no apparent relation with absorption capacity. A temperature either higher or lower than $20^{\circ} \mathrm{C}$ can lead to notably higher absorption capacity of SAP. Prediction of specific surface of SAP voids based on measured absorption capacity and calculation seems promising, as it agrees with the specific surface measured directly by air void analysis. During the preparation of differently sized SAP, it was realized that the order of rinsing and sieving influences the registered size distribution of SAP particles.
\end{abstract}

Keywords Superabsorbent polymer, absorption capacity, specific surface, sieving, robustness 


\section{Introduction}

Superabsorbent polymer (SAP) is a multi-functional concrete additive, which has been subject to continuous research for two decades [1,2] and received worldwide interest [3, 4]. When mixed with cement and water, SAP absorbs liquid and swells. When the relative humidity drops e.g. as a result of cement hydration, water is gradually released from the swollen SAP and supplied to the cement paste [1]. The released water can mitigate autogenous shrinkage [2-7], reduce the porosity of cement paste [8], and seal $[9,10]$ or heal cracks [11-13]. Meanwhile, gas-filled voids are created as SAP particles give off water and shrink. A well-controlled air void system both in relation to void content and spacing factor is advantageous to the frost resistance of concrete [14], and the gas-filled voids created by SAP can provide frost protection similar to voids created by an air-entraining agent $[15,16]$.

The amount of liquid that SAP particles are able to absorb (i.e. the absorption capacity of $\mathrm{SAP}$ ) is critical to concrete mix design. For example, if more water is added to compensate SAP water absorption than what is actually absorbed by SAP, the extra water increases the water-to-cement ratio $(w / c)$ and thus changes all concrete properties related to $w / c$. When the aim of implementing SAP is to design frost-resistant concrete, an accurate value for the absorption capacity ensures a targeted void content and spacing factor, as the diameter increase ratio depends on the absorption capacity.

In principle, the absorption capacity of any batch of SAP to be used in a concrete mix 20 should be tested prior to implementation. However, some parameters related to mixing and curing may have an influence on the absorption capacity. For example, if a certain batch of SAP exhibits almost constant absorption capacity independent of its diameter, the implication is that the SAP absorption capacity is robust against particle size. On this basis a ready-mix plant may benefit from avoiding unnecessary measurements with particle sizes being a variable. As a starting point, the following variables that might be relevant for both research and industry are selected for survey:

- Cement type: Cement types differ in alkali content, or proportion of clinker constituents and several other factors;

- $w / c$ : It plays a dominant role in pore liquid composition, especially the concentration of calcium ions [17];

- Concrete additive: Superplasticizers are frequently used and therefore particularly 
relevant to include;

- Particle size of SAP: If designing the void structure as suggested by [16], absorption capacity and dry SAP particle size distribution are needed as inputs, but it is also important to know if the absorption capacity is size dependent;

- Mixing time: In particular ready-mix concrete may be subject to different duration before being placed depending on travel distance, traffic, etc., and the chemical composition of the pore liquid changes over time;

- Mixing and curing temperature: Temperature affects the kinetics of cement hydration, water diffusion and SAP water sorption.

A direct way to obtain the absorption capacity of SAP in cement-based materials is to compare dry SAP volume with the volume of voids created by SAP in hardened cement paste, mortar or concrete. On the contrary, measurements in an artificial solution (e.g. cement slurry filtrate) as proposed by many may deviate considerably from the absorption capacity of SAP in cement paste or concrete [18]. The main reason is that the liquid composition and the ion transport condition in an artificial solution do not correspond to those in a hardening cement paste. Interstitial water in the "artificial" test also contributes to the deviation. A number of methods based on cement paste or concrete can be adopted to carry out air void analysis that provide reliable data on swollen SAP size. One such method is optical microscopy based on ground plane sections. Advantages of this method include:

- Optical microscopes are commonly found in laboratories and straightforward to operate;

- Preparation of sections by grinding is uncomplicated;

- The accuracy of this method is well documented by interlaboratory tests [19, 20];

- The efficiency can be significantly improved by computer-aided analyses of specimens with [21, 22] or without [23] color enhancement.

By means of optical microscopy, air void analyses have shown agreement between SAP absorption capacity in cement paste and SAP absorption capacity in concrete [18], i.e. a possible influence of aggregate due to e.g. physical restraint on the swelling of SAP seems minor.

In the light of this, the aim of the present study is to identify parameters relevant to SAP 30 absorption capacity in cement paste. Examined parameters are cement type, $w / c$ ratio, SAP particle size, mixing time, and temperature during mixing and curing. Air void analysis by 
optical microscopy is used to determine absorption capacity. One type of commonly used SAP is investigated in the paper.

\section{Materials and methods}

\subsection{Materials}

\subsubsection{Superabsorbent polymers (SAP)}

A covalently crosslinked acrylamide/acrylic acid copolymer is used in this study. This type of SAP has been used for several studies and has proven suitable for use in concrete $[6,9,16$, 24-28]. The SAP used in this study is produced by suspension polymerization and consists mainly of spherical particles. Its dry density is $1.5 \mathrm{~g} / \mathrm{cm}^{3}$.

\subsubsection{Cement}

Four types of cement were used, designated by LA, WPC, HA and LL. A difference in alkali content is found between the Portland cements WPC, LA and HA (in an ascending order). LL is a Portland-limestone cement, and therefore it contains more limestone filler than the other types of cement.

LA, WPC and LL are manufactured by Aalborg Portland in Denmark, whereas HA is a product of Cementa in Sweden. All four cements conform to EN 197-1. Density, fineness and phase composition are listed in Table 1.

Table 1 Properties of cements (according to the manufacturers). The phase composition is calculated according to Bogue.

\begin{tabular}{ccccccccc}
\hline \multirow{2}{*}{ ID } & \multirow{2}{*}{$\begin{array}{c}\text { Classification } \\
\text { according to EN 197-1 }\end{array}$} & \multirow{2}{*}{$\begin{array}{c}\text { Density } \\
{\left[\mathrm{kg} / \mathrm{m}^{3}\right]}\end{array}$} & \multicolumn{4}{c}{ Phase composition [wt\%] } & Blaine \\
& & $\mathrm{C}_{3} \mathrm{~S}$ & $\mathrm{C}_{2} \mathrm{~S}$ & $\mathrm{C}_{3} \mathrm{~A}$ & $\mathrm{C}_{4} \mathrm{AF}$ & $\mathrm{Na}_{2} \mathrm{O}$ eq. & \\
\hline LA & CEM I 52.5N (LA) & 3140 & 63 & 12 & 8 & 12 & 0.58 & 420 \\
WPC & CEM I 52.5 R - SR5 (EA) & 3140 & 67 & 20 & 5 & 1 & 0.25 & 390 \\
HA & CEM I 52.5 R (HA) & 3125 & 55 & 18 & 7 & 10 & 1.0 & 520 \\
LL & CEM II/A-LL 52.5 N (LA) & 3070 & 61 & 11 & 8 & 12 & 0.58 & 590 \\
\hline
\end{tabular}

\subsubsection{Superplasticizer}

A polycarboxylate-based superplasticizer (SPT) with $23 \%$ solid content and density of 1.05 $\mathrm{g} / \mathrm{cm}^{3}$ was used. Its equivalent $\mathrm{Na}_{2} \mathrm{O}$ content is lower than $2 \%$ according to the manufacturer. 


\subsection{Pretreatment of SAP}

When dividing SAP particles into size intervals by sieving, it is important that the moisture state prior to sieving is well-defined, as it influences the particle size. It is also important that the moisture state is well-defined, when SAP is added to the cement paste. Therefore, the well-defined moisture state needs to be established, e.g. by drying [16], to take into account that the moisture state may change during the pretreatment process.

SAP particles are commonly sieved by a stack of metal-mesh sieves [29-31] shaken by a vibrator that generates vertical movement. It is speculated if manual sieving, which creates shear, would improve the sieving quality. SAP should also be rinsed, if there is surfactant remaining on SAP particles from its production [16, 32]: the dry surfactant may "glue" SAP particles into agglomerates and thus result in individual SAP particles being smaller than given by the sieve size. It is therefore relevant to investigate if the sieving quality is influenced by the order of rinsing and sieving, and if there is a difference in the sieving quality between manual sieving and mechanical sieving. Prior to absorption capacity tests, the SAP was divided into three portions, each pretreated in a procedure (A, B, or $\mathrm{C})$, and the size distribution of each portion was registered after the pretreatment.

- Procedure A: drying, mechanical sieving, rinsing, drying;

- Procedure B: rinsing, drying, mechanical sieving, drying;

- Procedure C: rinsing, drying, manual sieving, drying.

Drying: The SAP was dried in a ventilated $50^{\circ} \mathrm{C}$ oven until constant mass was obtained (24 hours).

Mechanical sieving: A sieving stack with SAP in the top sieve was covered by a lid, and shaken by a motorized vibrator for 15 minutes. Each sieve retaining SAP was weighed. The sieving stack was shaken by the vibrator for additional 5 minutes, until the mass change of retained SAP on any sieve before and after the additional sieving was less than $1 \%$, as per BS/EN 933-1 [33]. Whenever the mass of retained SAP exceeded a critical mass $m_{c}$, the SAP was divided into small portions, each less than $m_{c}$ in mass. Each portion was sieved after the previous portion had been removed from the sieve and collected. The critical mass $m_{c}$ (in gram) is defined by Eq. 1, on the basis of BS/EN 933-1 [33]:

$$
m_{c}=\eta \cdot \frac{A \sqrt{d}}{200}
$$


where $\eta$ being 0.6 is the relative density of SAP to normal weight aggregate, $A$ is the area of the sieve (in $\mathrm{mm}^{2}$ ), $d$ is the aperture size of the sieve (in $\mathrm{mm}$ ).

Manual sieving: With a lid on, the sieving stack was gently shaken for 10 seconds to allow particles to free fall. Manual sieving was performed on one sieve after another (topbottom). For each sieve, the SAP was rubbed back and forth along the sieve mesh for 5 minutes by fingers (with a rubber glove on) with pressure. The rubbing was re-conducted for 5 minutes, until the mass of retained SAP on this sieve before and after the additional sieving was less than $1 \%$ [33]. As in the mechanical sieving process, the mass of SAP on any sieve was controlled to be less than $m_{c}$, see Eq. 1 .

Rinsing: The SAP was rinsed with ethanol following the procedure described by Laustsen et al. [16] to remove possible surfactant.

\subsection{Cement paste preparation}

Twenty cement paste specimens were prepared. For each mix, pretreated SAP (procedure C) was dry-mixed manually with cement. Then the mixed dry material was added to liquid (deionized water, possibly pre-mixed with superplasticizer). The total amount of water is a sum of "basic" water $\left(w_{b}\right)$ and water required for SAP absorption, i.e. "entrained" water $\left(w_{e}\right)$. The entrained water was assumed to be 20 times the mass of SAP, which is the result from a pre-test using the same mix proportion as in mix 1. Table 2 shows the composition of each mix. Mixing was done under vacuum at the temperature shown in Table 2 after which the cement paste was poured into a $250 \mathrm{ml}$ bottle with care to minimize entrapped air. A previous work shows that the vacuum is capable of removing air bubbles produced during mixing [18], implying that all voids in hardened cement paste are SAP voids. The bottle was sealed and until cutting it was stored at the temperature shown in Table 2; during the first 24 hours after mixing the bottle was rotated. 
Table 2 Composition, mixing time, and temperature during mixing and curing of cement paste specimens. Deviations from the reference composition are shown in bold.

\begin{tabular}{|c|c|c|c|c|c|c|c|c|c|c|}
\hline \multirow{2}{*}{ ID } & \multirow{2}{*}{$\begin{array}{l}\text { Cement } \\
\text { type }\end{array}$} & \multirow{2}{*}{$w_{b} / c$} & \multirow{2}{*}{$\begin{array}{l}\text { SAP diameter } \\
{[\mu \mathrm{m}]}\end{array}$} & \multicolumn{4}{|c|}{ Mass [g] } & \multirow{2}{*}{$\begin{array}{c}\text { Volume } \\
{\left[\mathrm{cm}^{3}\right]}\end{array}$} & \multirow{2}{*}{$\begin{array}{l}\text { Mixing } \\
\text { time }\end{array}$} & \multirow{2}{*}{ Temp. } \\
\hline & & & & Cement & SAP & Water & SPT & & & \\
\hline $1-5$ & LA & 0.45 & $90-106$ & 500.0 & 3.0 & 285.0 & 0.0 & 446.2 & $3 \min$ & $20^{\circ} \mathrm{C}$ \\
\hline 6 & WPC & 0.45 & $90-106$ & 500.0 & 3.0 & 285.0 & 0.0 & 446.2 & $3 \mathrm{~min}$ & $20^{\circ} \mathrm{C}$ \\
\hline 7 & HA & 0.45 & $90-106$ & 500.0 & 3.0 & 285.0 & 0.0 & 447.0 & $3 \mathrm{~min}$ & $20^{\circ} \mathrm{C}$ \\
\hline 8 & $\mathbf{L L}$ & 0.45 & $90-106$ & 500.0 & 3.0 & 285.0 & 0.0 & 449.9 & $3 \mathrm{~min}$ & $20^{\circ} \mathrm{C}$ \\
\hline 9 & LA & 0.30 & $90-106$ & 500.0 & 3.0 & 202.3 & 10.0 & 373.1 & $3 \mathrm{~min}$ & $20^{\circ} \mathrm{C}$ \\
\hline 10 & LA & 0.35 & $90-106$ & 500.0 & 3.0 & 227.3 & 10.0 & 398.1 & $3 \mathrm{~min}$ & $20^{\circ} \mathrm{C}$ \\
\hline 11 & LA & 0.45 & $90-106$ & 500.0 & 3.0 & 277.3 & 10.0 & 448.1 & $3 \mathrm{~min}$ & $20^{\circ} \mathrm{C}$ \\
\hline 12 & LA & 0.60 & $90-106$ & 500.0 & 3.0 & 360.0 & 0.0 & 521.2 & $3 \mathrm{~min}$ & $20^{\circ} \mathrm{C}$ \\
\hline 13 & LA & 0.45 & $45-50$ & 500.0 & 3.0 & 285.0 & 0.0 & 446.2 & $3 \mathrm{~min}$ & $20^{\circ} \mathrm{C}$ \\
\hline 14 & LA & 0.45 & $150-160$ & 500.0 & 3.0 & 285.0 & 0.0 & 446.2 & $3 \mathrm{~min}$ & $20^{\circ} \mathrm{C}$ \\
\hline 15 & LA & 0.45 & 180-212 & 500.0 & 3.0 & 285.0 & 0.0 & 446.2 & $3 \mathrm{~min}$ & $20^{\circ} \mathrm{C}$ \\
\hline 16 & LA & 0.45 & $90-106$ & 500.0 & 3.0 & 285.0 & 0.0 & 446.2 & $0.5 \mathrm{~h}$ & $20^{\circ} \mathrm{C}$ \\
\hline 17 & LA & 0.45 & $90-106$ & 500.0 & 3.0 & 285.0 & 0.0 & 446.2 & $1.0 \mathrm{~h}$ & $20^{\circ} \mathrm{C}$ \\
\hline 18 & LA & 0.45 & $90-106$ & 500.0 & 3.0 & 285.0 & 0.0 & 446.2 & $1.5 \mathrm{~h}$ & $20^{\circ} \mathrm{C}$ \\
\hline 19 & LA & 0.45 & 90-106 & 500.0 & 3.0 & 285.0 & 0.0 & 446.2 & $3 \mathrm{~min}$ & $5^{\circ} \mathrm{C}$ \\
\hline 20 & LA & 0.45 & $90-106$ & 500.0 & 3.0 & 285.0 & 0.0 & 446.2 & $3 \mathrm{~min}$ & $40^{\circ} \mathrm{C}$ \\
\hline
\end{tabular}

As mentioned the mixing of each paste was done at the temperature shown in Table 2.

Materials, mixing bowl and beater were stored for $12 \mathrm{~h}$ at the relevant temperature prior to mixing.

All mixes were initially vacuum-mixed for 3 minutes continuously. For mixes 16-18,

5 subsequent mixing was done as shown in Fig. 1. During the non-mixing intervals, a lid was put on top of the mixing bowl to reduce carbonation and evaporation.

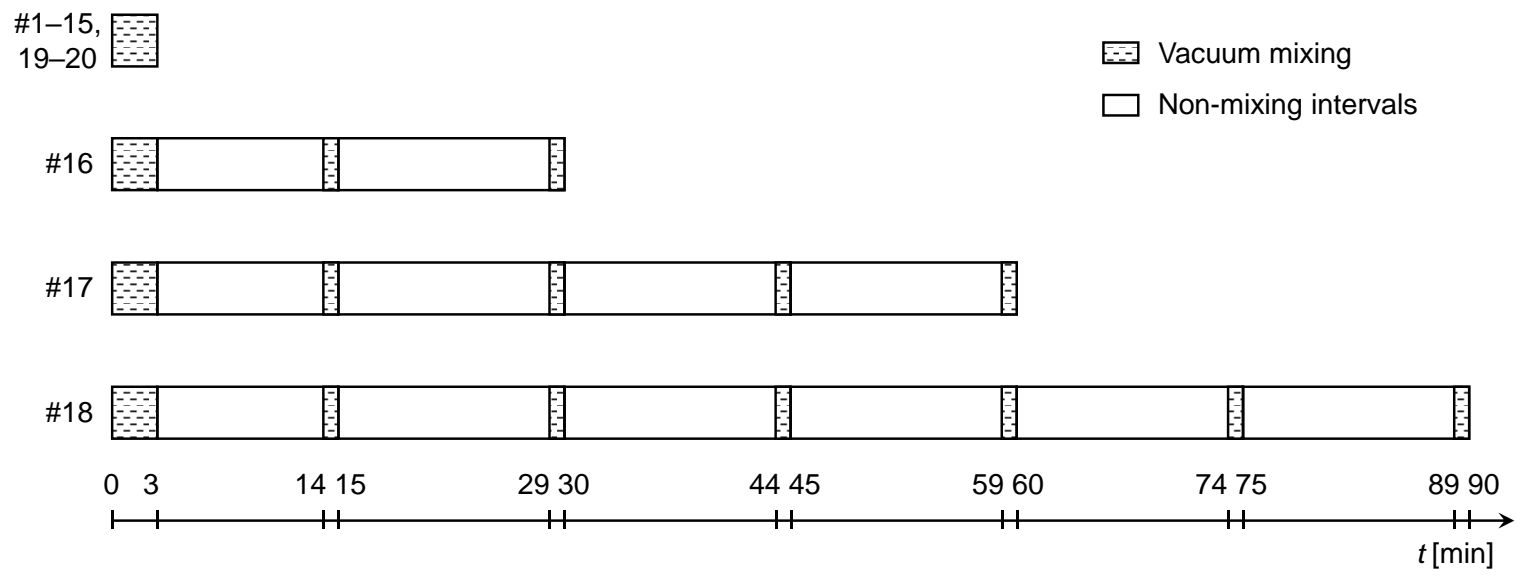

Fig. 1 Mixing regime. During the non-mixing intervals, a lid was put on top of the mixing bowl to reduce carbonation and evaporation.

\section{$10 \quad 2.4$ Air void analyses of cement paste}

At the age of 7 days, the specimens were cut lengthwise. A sample with a thickness of $\sim 1 \mathrm{~cm}$ and a $6 \times 8 \mathrm{~cm}^{2}$ cross section was cut from the center of each specimen. The two parallel, $1 \mathrm{~cm}$ 
separated surfaces of the sample were ground with silicon carbide abrasive papers with grit sizes of $75,35,17.5$ and $12.5 \mu \mathrm{m}$ successively. Due to the characteristic length scale of paste (with no aggregates), sections $10 \mathrm{~mm}$ apart can be considered independent sections. The full surface of each section was scanned by a stereo microscope (Nikon SMZ25) with a motorized stage, and the captured images were stored for void parameter analysis. The magnification for scanning was $80 \times$ for mix 13 , and $50 \times$ for the other mixes.

\subsubsection{Measurements}

For all 20 mixes, the air void system was investigated according to the linear-traverse method in ASTM C457 [34]. Thirty traverse lines were applied on the scanned image of each plane

10 section. The length of each line was $30 \mathrm{~mm}$. The separation between adjacent lines was 1 $\mathrm{mm}$, which ensured that no void was intersected more than once. For each void intersected, the length traversed $T_{i}$ was registered. The number of traversed voids $N$ was also registered. Summing up $T_{i}(1 \leq i \leq N)$ gave $T_{v}$, the length traversed through voids. Table 3 gives the values (if constant among mixes) and definitions of properties that are registered in the air void analyses. An example of an examined section is shown in Fig. 2.

Table 3 Properties involved in the air void analyses of cement pastes using the lineartraverse method in ASTM C457 [34].

\begin{tabular}{cccc}
\hline Symbol & Definition & Value (if constant) & Unit \\
\hline$T_{t}$ & Total length of traverse lines & $900^{\mathrm{a}}$ & $\mathrm{mm}$ \\
$T_{v}$ & Length traversed through voids & - & $\mathrm{mm}$ \\
$N$ & Number of voids intersected by traverse lines & - & - \\
\hline${ }^{a}$ Value for one section. Two sections were examined for each mix.
\end{tabular}


(a)

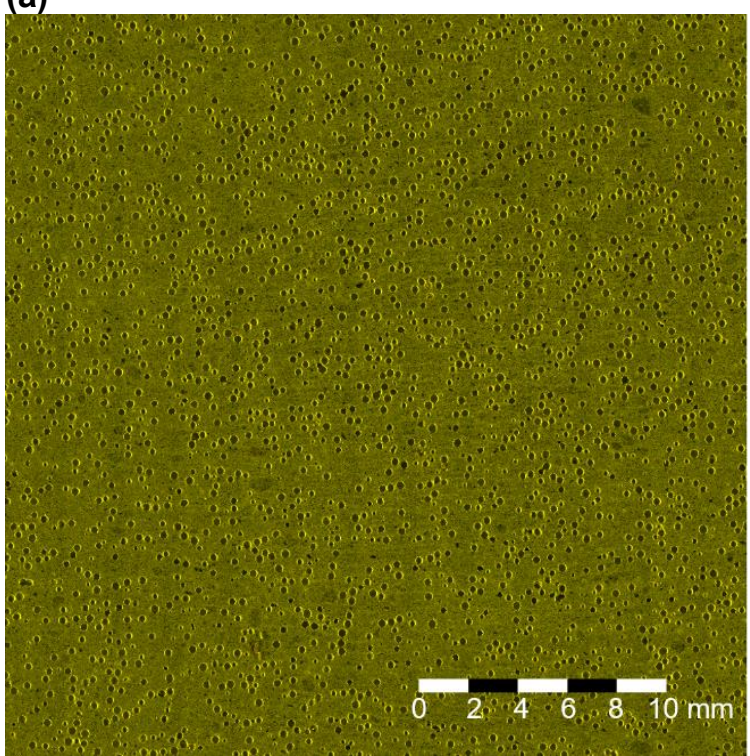

(b)

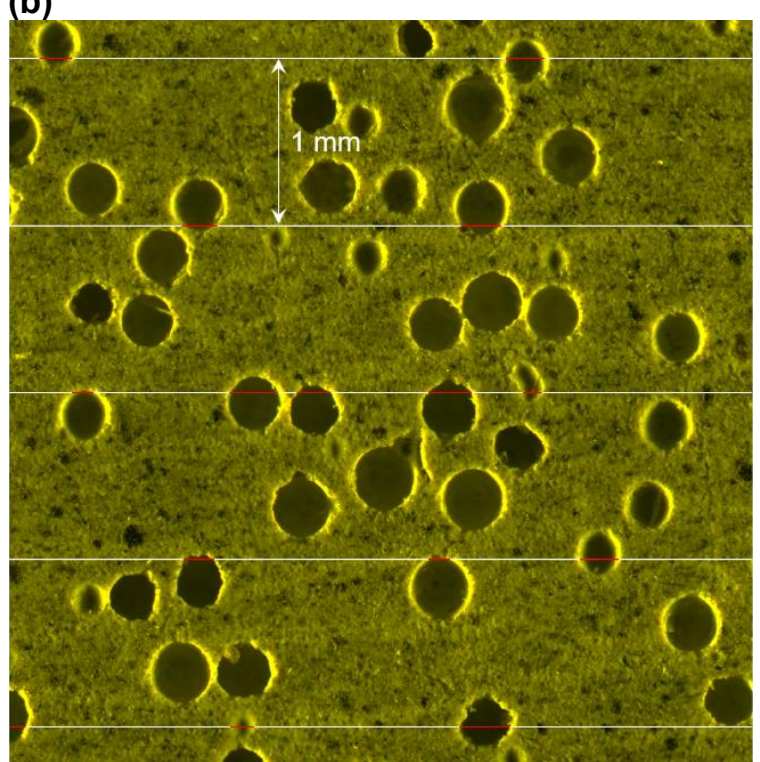

Fig. 2 A hardened cement paste specimen (specimen 3 ) under air void analysis using the linear-traverse method:

(a) scanned image of a $3 \mathrm{~cm} \times 3 \mathrm{~cm}$ ground section; (b) local enlarged view, where white lines designate the traverses and red segments are the lengths traversed across voids (i.e. chord lengths). All voids are assumed to be SAP voids, see Section 2.3. Hydration products, with a thickness of less than 1/10 of the void diameter, and desorbed SAP particles are seen inside the rim of some of the SAP voids. The chord lengths are measured from the outer rim of the SAP voids.

\subsubsection{Absorption capacity}

Assuming that the volume of swollen SAP is the sum of the volume of dry SAP and the volume of absorbed water, the SAP absorption capacity AC (gram per gram SAP) and the diameter increase ratio upon water absorption $k$ can be calculated by Eqs. 2 and 3, respectively:

$$
\begin{aligned}
& A C=\frac{\rho_{w} \cdot\left(V_{c p} \cdot \frac{T_{v}}{T_{t}}-V_{S A P}\right)}{m_{S A P}} \\
& k=\sqrt[3]{1+\frac{\rho_{S A P}}{\rho_{w}} \cdot A C}
\end{aligned}
$$

where $V_{c p}$ is the volume of cement paste; $\rho_{S A P}, m_{S A P}$ and $V_{S A P}$ are density, mass and volume of dry SAP; $\rho_{w}$ is the density of water; $T_{v} / T_{t}$ is the void content in cement paste (definitions of $T_{v}$ and $T_{t}$ are given in Table 3). 


\subsubsection{Specific surface (predicted)}

SAP voids, i.e. voids left by shrunken SAP, can be used to design the void structure of cement-based materials. Powers' spacing factor $L$, given in Eq. 4 , is an important void characteristic, which is inversely proportional to specific surface $\alpha$ [35]:

$$
L= \begin{cases}\frac{p}{A} \cdot \frac{1}{\alpha} & \text { for } \frac{p}{A}<4.342 \\ \frac{3}{\alpha}\left(1.4\left(\frac{p}{A}+1\right)^{1 / 3}-1\right) & \text { for } \frac{p}{A} \geq 4.342\end{cases}
$$

where $p$ is the paste content ( $\%$ of concrete volume), $A$ is the air content ( $\%$ of concrete volume).

Potentially, the specific surface of SAP voids can be predicted from the dry SAP particle size and the diameter increase ratio upon swelling $k$, and thus a void structure with a targeted spacing factor can be generated.

For unisized spheres with a diameter of $D$, the specific surface $\alpha$ is $6 / D$. In the present study where spheres have a span of diameters, we define $D_{r e p}=6 / \alpha$ as the representative diameter of all spheres. As a starting point, $D_{\text {rep }}$ in this study is assumed to be the arithmetic mean of the lower and upper bounds of the SAP diameter range. Thus the specific surface of

15 SAP voids in each mix can be predicted by Eq. 5 based on diameter change:

$$
\alpha_{p}=\frac{12}{k\left(D_{1}+D_{2}\right)}
$$

where $\alpha_{p}$ is the predicted specific surface based on diameter change, $D_{1}$ and $D_{2}$ are the lower and upper bounds of diameter range of dry SAP in a mix (see Table 2), $k$ is the diameter increase ratio of SAP in a mix defined by Eq. 3 .

\subsubsection{Specific surface (measured)}

It is important to know the accuracy of the predicted specific surface of SAP voids. The specific surface of SAP voids was measured for all mixes.

Specific surface is calculated according to ASTM C457 [34] by Eq. 6:

$$
\alpha_{m}=\frac{4}{\bar{l}}
$$

25 where $\bar{l}$ is the average chord length. The average chord length can be calculated by Eq. 7, according to method A (linear-traverse) as described by ASTM C457 [34]:

$$
\bar{l}=\frac{T_{v}}{N}
$$

where definitions of inputs are given in Table 3. 
Combining Eqs. 6 and 7 results in Eq. 8, which can be used for determining the measured specific surface.

$$
\alpha_{m}=\frac{4 N}{T_{v}}
$$

\section{Results}

\subsection{Sieving quality}

Fig. 3 shows the size distribution of SAP particles pretreated by different procedures.

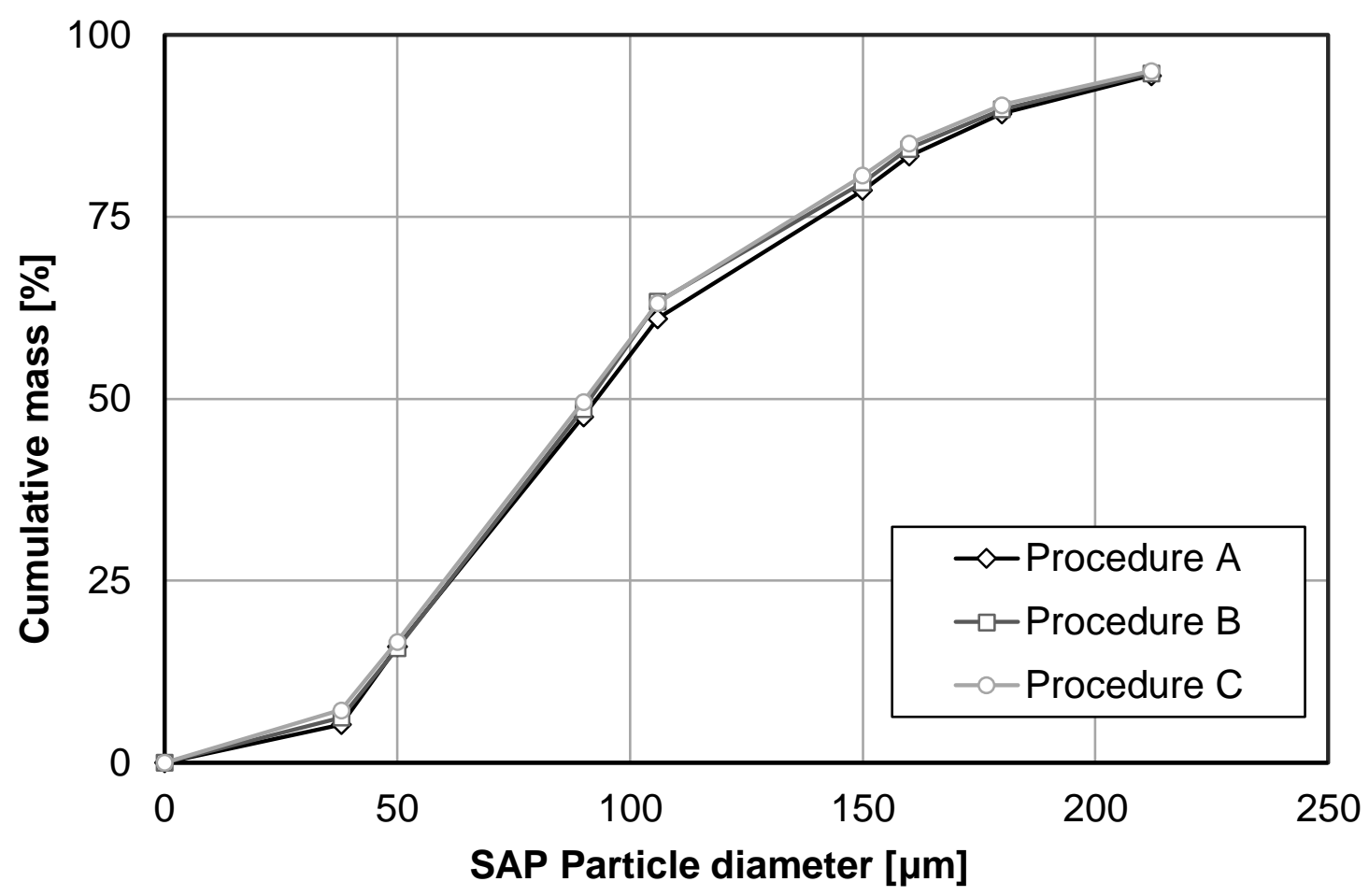

Fig. 3 Particle size distribution of SAP pretreated by different procedures: (A) drying, mechanical sieving, rinsing, drying; (B) rinsing, drying, mechanical sieving, drying; (C) rinsing, drying, manual sieving, drying.

Fig. 4 shows differently sized SAP pretreated by procedure C. Procedure C involves rubbing of the (dry) SAP particles, which creates shear. However, light microscopy showed that the pretreated SAP particles maintained their spherical shape, indicating that the gentle rubbing did not disintegrate the individual particles. Cavities inside the SAP particles are observed in about half of the particles, which may be mistaken for smaller particles. This causes a 2\% error in the density of SAP and, as a result, on dry SAP volume. The absorption capacity will be similarly influenced by this phenomenon and is thus insignificant. 

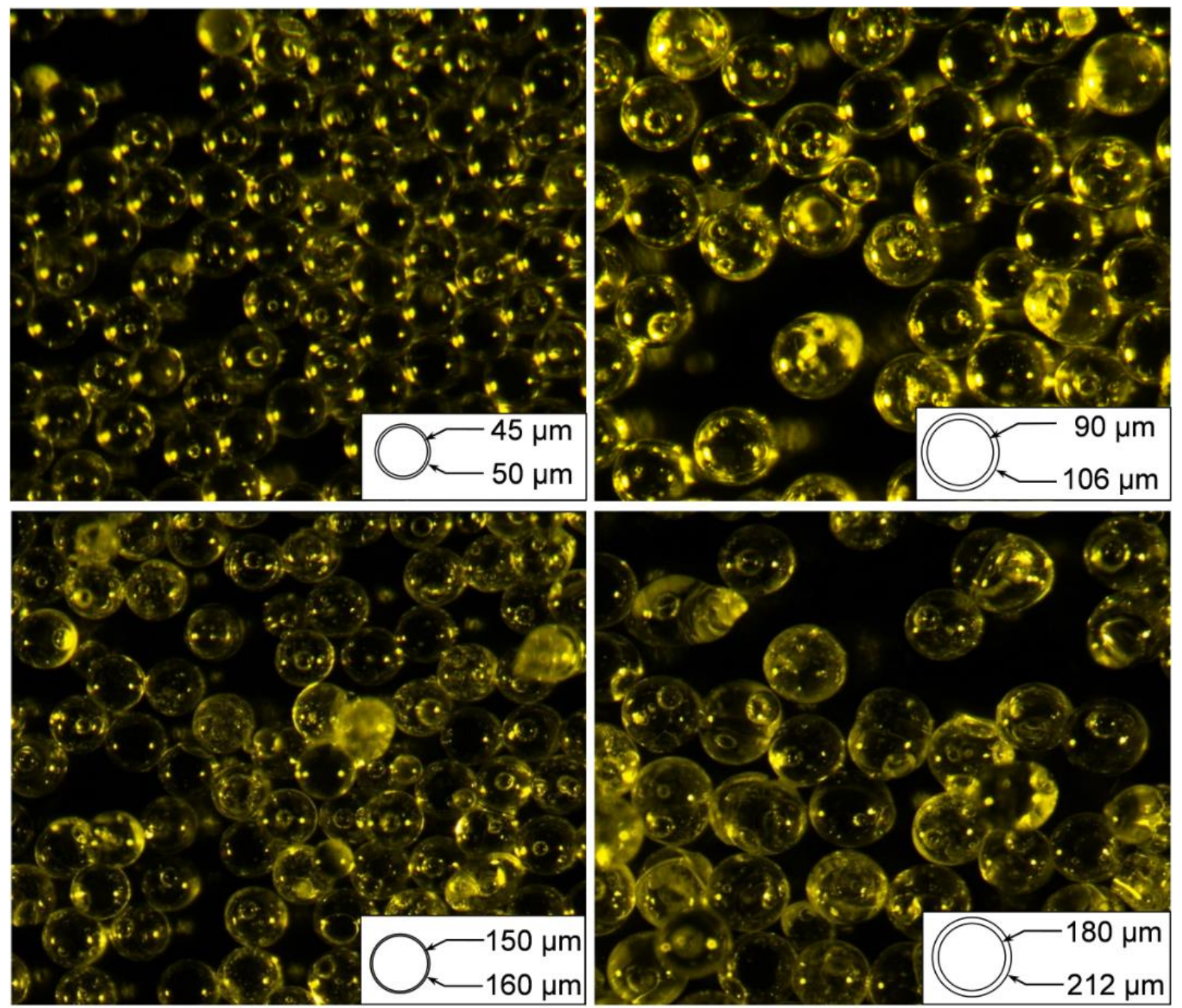

Fig. 4 Optical microscopic images of SAP (pretreated by procedure C) in four size fractions as indicated by the upper and lower diameter bounds. Cavities inside the SAP particles are observed, which may be mistaken for smaller particles.

\subsection{Absorption capacity of SAP in cement pastes}

Mixes 1 to 5 have identical composition as well as mixing and curing regimes. The absorption capacity of SAP $(A C)$ in these specimens are 21.2, 20.5, 20.7, 21.9 and $20.7 \mathrm{~g} / \mathrm{g}$, as shown in Fig. 5(a). The average of the five measurements is $21.0 \mathrm{~g} / \mathrm{g}$, and the standard deviation $\sigma$ is $0.6 \mathrm{~g} / \mathrm{g}$. The coefficient of variance for the five measurements is $2.7 \%$.

In Fig. 5(b-f), measured absorption capacities for all 20 specimens are grouped according to the examined variables. The average of the reference mixes (1-5) is displayed as "avg. REF" in each sub-figure for comparison. Dotted lines represent $\pm 2 \sigma$ deviation from the average of mixes $1-5$, whereas dashed lines represent $\pm 15 \%$ deviation (the reasons for these lines are explained in Sections 4.2 and 4.3). 
(a)

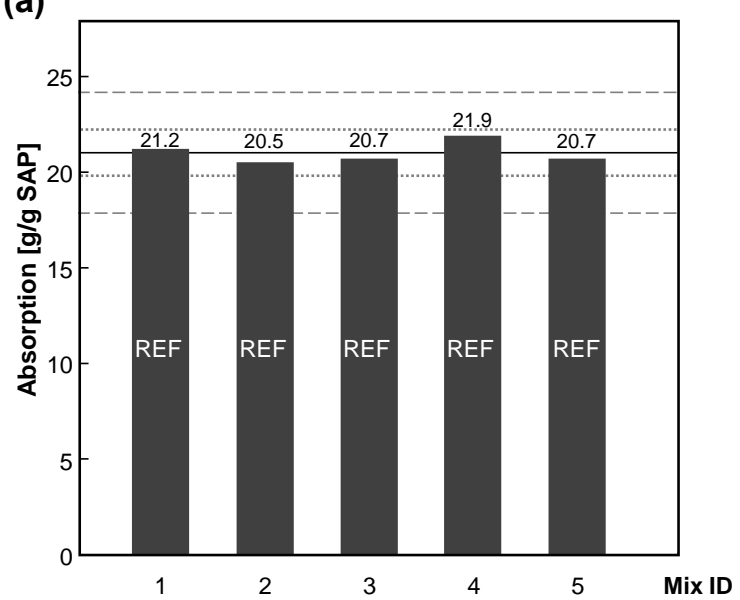

(c)

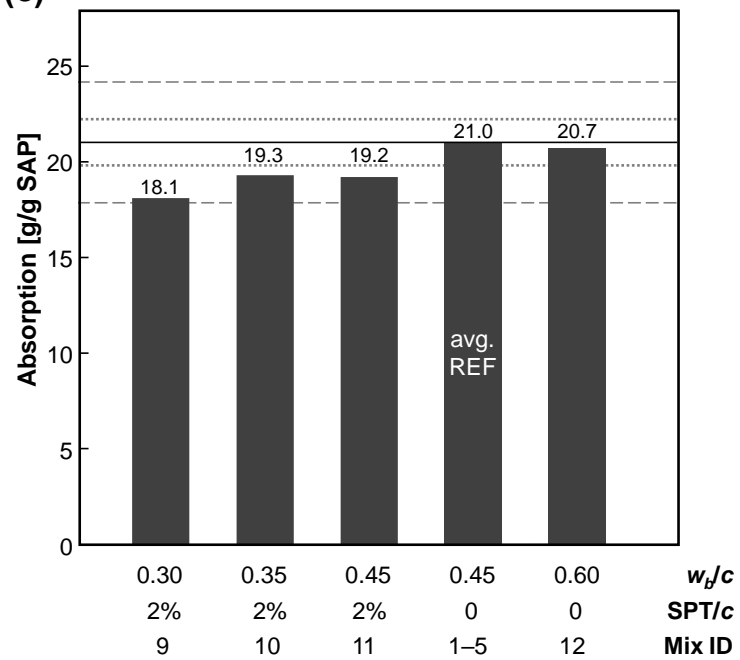

(e)

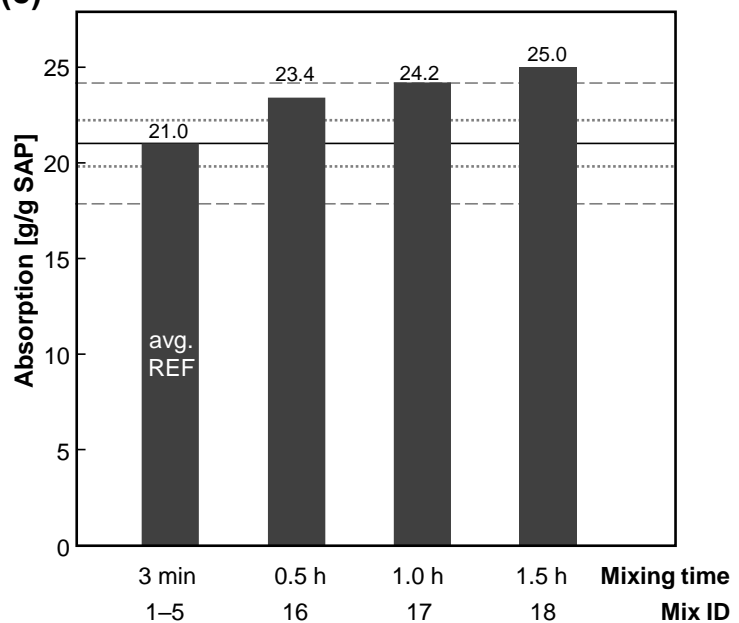

(b)

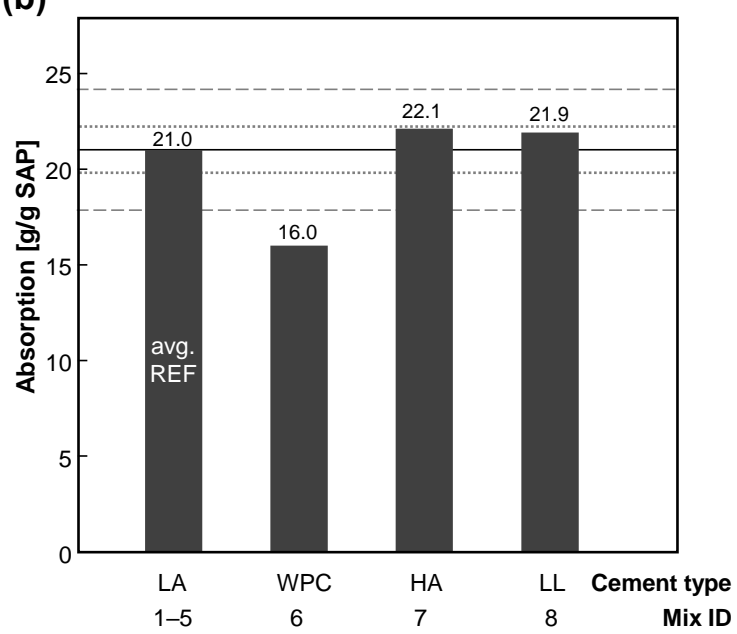

(d)

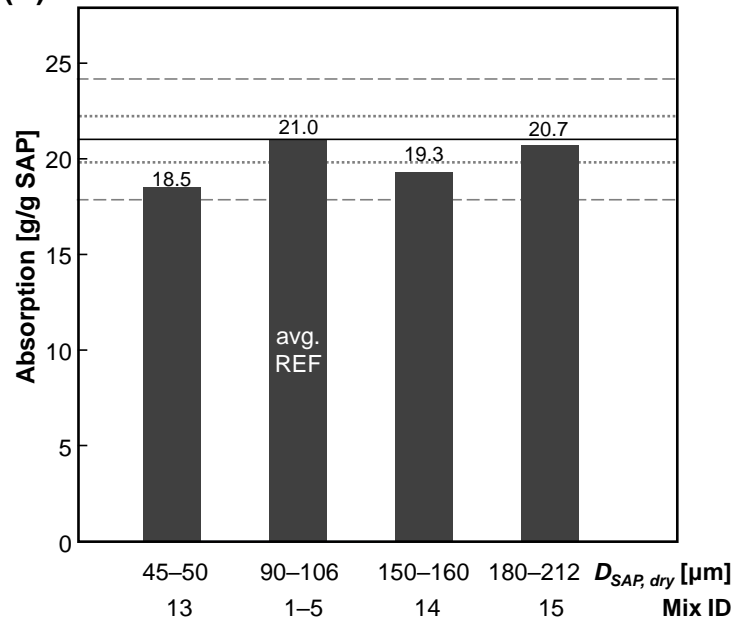

(f)

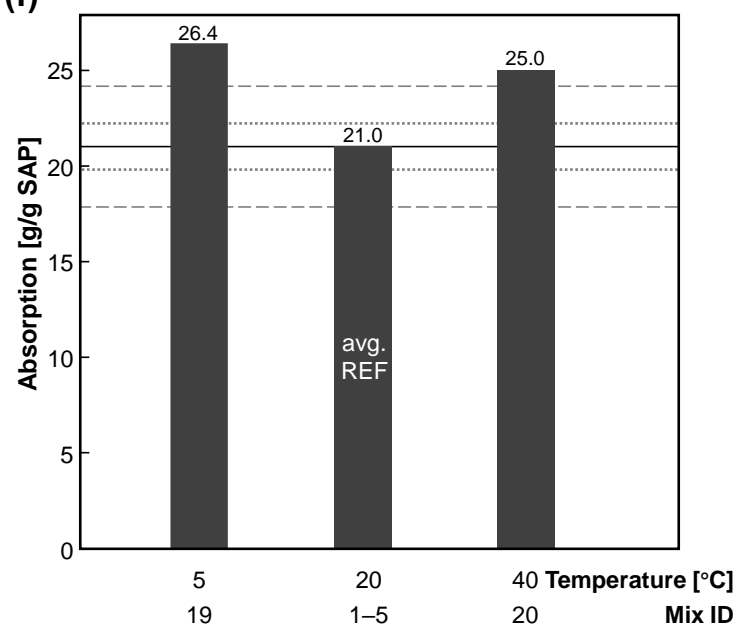

Fig. 5 SAP absorption capacity of (a) the five reference mixes and as function of (b) cement type, (c) $w_{b} / c$ and superplasticizer, (d) dry SAP diameter, (e) mixing time, and (f) temperature during mixing and curing. The bars labeled "REF" are results from mixes 1-5. Solid lines and "avg. REF" indicate the average of mixes 1-5. Dotted lines (...) represent $\pm 2 \sigma$ deviation from the average of mixes $1-5$, whereas dashed lines (- - -) represent $\pm 15 \%$ deviation. 


\subsection{Specific surface of SAP voids}

Fig. 6 shows the predicted specific surface $\alpha_{p}$ vs. measured specific surface $\alpha_{m}$ for all 20 mixes. Definitions of $\alpha_{p}$ and $\alpha_{m}$ are given in Eq. 5 and Eq. 8, respectively.

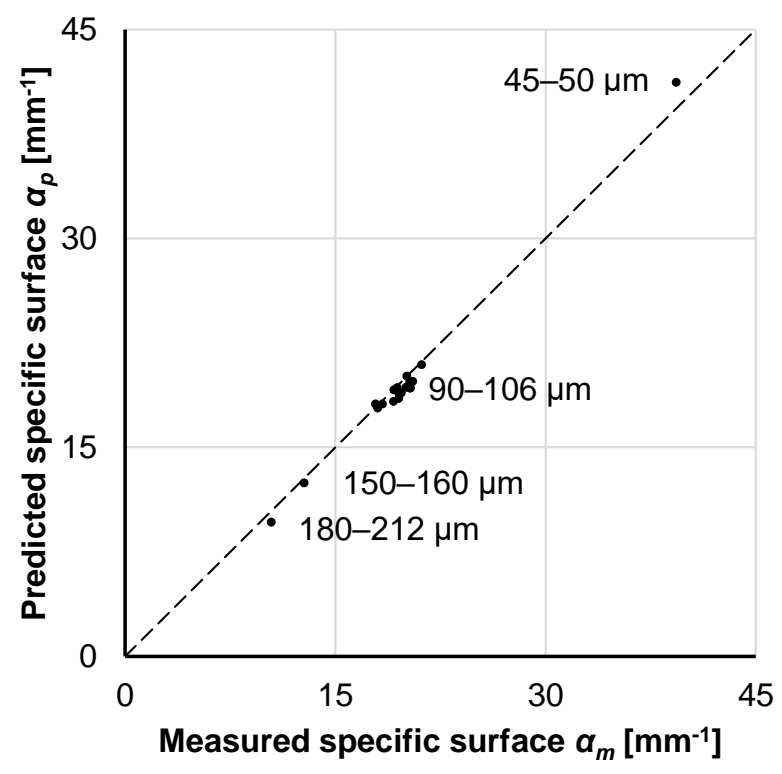

$5 \quad$ Fig. 6 Predicted specific surface $\alpha_{p}$ vs. measured specific surface $\alpha_{m}$. Numbers denote the dry SAP diameter for each mix; the points near the "90-106 $\mu$ m" label are results from 17 mixes. Dashed line is the 1:1 relation.

\section{Discussion}

\subsection{Sieving quality}

10 As checked by microscopic images in Fig. 4, the quality of manual sieving (procedure C) is satisfactory, despite some minor agglomeration that cannot be totally eliminated. In Fig. 3, the curves for procedure $\mathrm{B}$ and $\mathrm{C}$ almost coincide. This means that mechanical sieving can achieve a sieving quality as good as manual sieving.

Another issue is whether sieving should be done before (procedure A) or after rinsing

15 (procedure B or C). In Fig. 3, the curve corresponding to procedure A is slightly shifted to the right, compared to the curves for procedures B and C. In other words, at all measured mesh sizes but one, the cumulative mass of SAP is smaller for procedure A than that for procedure $\mathrm{B}$ or $\mathrm{C}$. This is likely due to particle agglomeration caused by the surfactant in procedure A, where the surfactant is present during sieving and is removed only after sieving. However, this effect is only minor: the largest relative difference in cumulative mass between procedure 
A and B occurs at $106 \mu \mathrm{m}$, where the cumulative mass for procedure B is 1.04 times that for procedure A.

Note that the discussion above is only valid when SAP is dried before and after sieving. It should be dried before sieving, since the storage or rinsing process could change the moisture state of SAP (rinsing with ethanol will imply drying). Drying should also be done after sieving (unless the next step is to rinse SAP with ethanol, as in procedure A), since the sieving process involves repeated shaking and weighing which could take enough time for SAP to absorb moisture and swell.

\subsection{Repeatability of the method to measure absorption capacity}

10 Regarding mixes 1 to 5 where the SAP dosage is $0.6 \%$ relative to cement mass, an $A C$ overestimation (assuming $21.0 \mathrm{~g} / \mathrm{g}$ is the true value) of $2 \sigma$ (i.e. overestimation by $5.4 \%$ ) results in a 0.007 increase in $w_{b} / c$, which is negligible. Assuming measurements of $A C$ to be normally distributed, the probability that an observation falls outside $A C \pm 2 \sigma$ is $4.6 \%$. This means that an observation within 2 times standard deviation from the reference value cannot be considered significantly different. Thus, the repeatability of measurements is acceptable. However, it is important to keep this uncertainty in mind, when interpreting the robustness of SAP absorption capacity against a certain parameter. This will be further explained in Section 4.3 .

\subsection{Robustness of SAP absorption capacity}

20 There is no set criterion for assessing if a SAP is robust or not in terms of absorption capacity. It depends mainly on the deviation of $w_{b} / c$ brought by the variance in SAP absorption capacity. Often, an acceptable $w / c$ variation in concrete production is 0.02 . According to Euronorm 206 [36], the concrete producer has to meet the declared $w / c$ within a range of \pm 0.02 (strictly, only the upper limit applies). Chinese standard, as another example, has a requirement on the maximum deviation of weighed ingredients from mix design [37], implying also a $w / c$ tolerance of \pm 0.02 . If assuming that the target SAP void content is $4 \%$ (the natural air content is typically $1 \%$, so in total the air content registered in the hardened concrete will then be $5 \%$ ), then 401 water per $\mathrm{m}^{3}$ concrete should be added to compensate the SAP water absorption (no matter the SAP absorption capacity; if the SAP absorption capacity

30 is low, then the SAP dosage will be high, and vice versa). If the concrete is going to be exposed to both de-icing chemicals and freezing, the $w / c$ should be lower than 0.45 and in 
some cases even lower than 0.40 . For these low $w / c$ ratios, $300 \mathrm{~kg}$ cement (or binder) per $\mathrm{m}^{3}$ concrete is a low cement content, but this can be used as a conservative estimate. When the $w_{b} / c$ is allowed to vary \pm 0.02 , the maximum allowable amount of surplus water (i.e. water that is expected to be absorbed by SAP but instead adds to the $w_{b} / c$ ) is 61 . The acceptable error of SAP absorption capacity in practice is thus, in this case, $61 / 401=15 \%$. In general, a concrete producer should not experience variance of absorption capacity of more than approx. $15 \%$ in daily production. When cement paste content is higher, the error that is acceptable can be set higher accordingly. On this basis, dashed lines in Fig. 5 indicate $\pm 15 \%$ deviation from the reference mix average.

The examined SAP polymer type is a common and relevant one (see Section 2.1.1). It should be borne in mind that the present robustness test is not exhaustive with respect to SAP types. Other SAP types may have different sensitivities towards different parameters. For example, the absorption capacity of SAP examined herein seems to be quite sensitive to binder type, but some other types of SAP may show less sensitivity towards this parameter.

\subsubsection{Binder type}

The binder type has a substantial influence on the absorption capacity of the SAP tested in the present study. This is evidenced by an approximately $75 \%$ absorption capacity in WPC cement paste compared with paste based on the reference cement (LA). Neither HA cement featuring a higher alkali content nor the LL cement with a higher content of limestone filler result in SAP absorption capacities that are significantly different from the SAP absorption capacity measured when using LA cement. As such, there does not seem to be a straightforward relation between cement composition and SAP absorption, so possibly the reason for the observations may be found in time-dependent ion composition phenomena. In any case, the test with different binder types is not exhaustive, and further investigations are needed to clarify the underlying cause of differences. Nevertheless, the finding in the present paper related to the importance of cement (binder) type implies that the concrete producer probably will have to measure absorption capacity for a certain mix design, i.e. absorption capacity cannot be declared on a technical data sheet, as it is binder-dependent.

\subsubsection{Water-to-cement ratio}

30 There seems to be an effect of $w / c$ ratio. However, the range $0.30-0.60$ is a very wide one. Even in this wide range of $w / c$ ratio, the deviation from the reference mixes is less than $15 \%$. 
Like this, if a concrete producer tests the SAP absorption capacity with the intended binder combination and the target $w / c$, then the effect of $w / c$ variation in the daily production can be neglected.

\subsubsection{Superplasticizer}

5 In a previous work [18], vacuum mixing was capable of removing bubbles in paste produced without additives, so presumably the bubbles were large, compared to entrained air voids that would probably be more difficult to remove by vacuum. Some SPTs have air-entraining abilities. In spite of this, the mix with SPT (mix 11) showed a 9\% lower apparent absorption capacity than mixes without SPT (everything else being equal). The difference is statistically

10 significant, as it is slightly more than two times standard deviation of the results from mixes $1-5$, but not a lot in the application perspective (less than 15\% deviation). Apparently, SPT can influence the absorption capacity of SAP in cement-based materials. Therefore, additives to be used need to be included in the pre-testing of the absorption capacity, in the same way as binder type should be taken into account.

This study initially involved two superplasticizers. However, tests with one of them failed (uneven distribution of SAP voids were observed in the hardened paste despite moderate flowability of fresh paste). This indicates that suitability of SPT as well as compatibility between SPT and SAP should be tested prior to using them in concrete.

\subsubsection{Particle size of SAP}

20 Absorption capacity of SAP at 45-50 $\mu \mathrm{m}$ and at $150-160 \mu \mathrm{m}$ in diameter is lower than two times standard deviation below average of the reference mixes. However, no systematic trend in absorption capacity with dry particle size is observed.

Research data on the size effect of SAP on absorption capacity has been scarce and inconclusive. Assmann assessed the absorption capacity of the same batch of SAP with both

25 rheology on fresh cement paste and image analysis of hardened cement mortar [38]. According to his measurements, absorption capacity seems to increase with particle size in both cases, but to different extents. More research needs to be carried out to conclude on the size effect.

The absorption kinetics of SAP particles, which may be size-dependent [39], will potentially influence the absorption capacity at the relevant point of stiffening of the 
cementitious system. However, when the aim is to measure absorption with the purpose of e.g. mix design of SAP concrete, it is more straightforward to measure on the cut specimen of hardened cement paste.

\subsubsection{Mixing time}

5 When the cement paste is subjected to repeated mixing before finally being placed in the mould 30 or 60 minutes after initial contact with water, the variation in SAP absorption capacity is smaller than $15 \%$ compared with the value measured when the cement paste is placed in the mould right after initial mixing, i.e. 3 minutes after first contact with water. For the mix that was placed in the mould after 90 minutes, the deviation slightly exceeds the $15 \%$ 10 limit.

Concrete has to be built in within 90 maturity minutes, according to Danish rules [40] and ASTM standard [41]. In this sense, the batch of SAP in this study seems to be fairly robust in terms of absorption capacity over the $1.5 \mathrm{~h}$ period, considering the repeatability of the method. If anything, the absorption capacity may slightly increase with time.

\subsubsection{Temperature}

SAP absorption capacity in both specimens mixed and cured at $5^{\circ} \mathrm{C}$ and $40^{\circ} \mathrm{C}$ are considerably higher than the one at $20^{\circ} \mathrm{C}$. It is evident that temperature has an impact on absorption capacity; however, the relation is unclear and should be further investigated. Among other things, measurements are needed to identify the temperature that leads to the lowest absorption capacity.

However, it should be noted that the present measurements cover a large span of temperature. Concrete shall never be delivered at a temperature lower than $5^{\circ} \mathrm{C}$, according to both EuroNorm [36] and Chinese standard [37]. When producing heated fresh concrete for castings during winter time, the temperature is typically $20^{\circ} \mathrm{C}$. This is also a typical temperature of fresh concrete during summer in Denmark. A start temperature higher than $35^{\circ} \mathrm{C}$ is prohibited in China [37], and it is not a realistic Danish scenario.

\subsection{Prediction of specific surface}

In Fig. 6, small deviations of individual points from the 1:1 line are observed. These deviations seem to be SAP-size dependant. It may be caused by the use of the mean of the size interval for predicting the specific surface (see Eq. 5). The size distribution curve (Fig. 3) 
indicates that size " $90-106 \mu \mathrm{m}$ " is close to the $50 \%$ fractile. " $45-50 \mu \mathrm{m}$ " is smaller so it is likely that there are more $50 \mu \mathrm{m}$ particles than $45 \mu \mathrm{m}$ particles in this size fraction. Using the average $47.5 \mu \mathrm{m}$ for predictions will therefore overestimate the specific surface. It is the other way around for size fractions " $150-160 \mu \mathrm{m}$ " and " $180-212 \mu \mathrm{m}$ ". Another possible explanation is that the operator does not always identify the smallest void cross sections, as the edges are often not as distinct as for larger void cross sections. The small SAP size is more sensitive to this phenomenon, as there are a higher number of small cross sections. Overlooking some of the small void cross sections reduces the registered void volume, but only marginally.

The present study points to that predictions of the specific surface of void systems generated by SAP can be made with acceptable accuracy, with dry particle size and absorption capacity as inputs. However, it has to be mentioned that the cases presented in this paper are special in the way that very narrow size intervals are used. With wider intervals, it will be difficult to calculate a trustworthy specific surface, because there are many assumptions (e.g. that the distribution within the interval is not skewed). From a point of view of frost resistance, it is safe, i.e. it underestimates the specific surface, to use the upper diameter of each size interval for predictions, but then the predicted specific surface may be far from the real specific surface. In such cases, it is better to measure.

When the aim is to calculate the void content (by volume) or the specific surface of the void structure, as is the case in the present study, the voids can have any shape, as long as they do not have a preferred orientation (spheres are deemed to satisfy this, but this may not necessarily be the case for other shapes). For example in the linear traverse method, the void volume can be obtained by the total chord length relative to the total traverse length, and this does not include assumptions about the particles being spherical. The voids have to be spherical, when calculating Power's spacing factor or to calculate the size distribution of voids, as the equations here are derived based on the assumption that particles are spherical.

\section{Conclusions}

When SAP is used in cement-based materials, it is important to know the extent by which absorption capacity may vary as a result of changing constituents, mix proportions or mixing procedure. The present study focuses on one commonly used type of SAP and tests the robustness of its absorption capacity in cement paste against several parameters. The SAP 
absorption capacity of the SAP tested in the present study is regarded as robust, if the deviation is less than $15 \%$, as this level of deviation is acceptable for many practical purposes.

The following conclusions regarding the robustness of the absorption capacity of the type of SAP investigated in the study can be drawn based on measurements on SAP void structure in hardened cement paste:

- The type of binder has a considerable influence on the absorption capacity of SAP. The absorption capacity registered in cement paste with the cement type that resulted in the highest absorption capacity was 38\% higher than the absorption capacity registered with the type of cement that lead to the lowest absorption capacity.

- Both a low temperature $\left(5^{\circ} \mathrm{C}\right)$ and a high temperature $\left(40^{\circ} \mathrm{C}\right)$ lead to absorption capacities of SAP that were more than $15 \%$ higher than the absorption capacity registered at the reference temperature $\left(20^{\circ} \mathrm{C}\right)$.

- The absorption capacity of SAP increased gradually with prolonged mixing time. When the mixing time was 90 minutes, the absorption capacity was almost $20 \%$ higher than when the mixing time was 3 minutes.

- When SAP was used together with a superplasticizer, the absorption capacity was reduced. The reduction was statistically significant, but less than $15 \%$. This points to that if SAP is going to be used together with other additives, these should be included in the pre-testing as they may influence the absorption capacity.

- SAP absorption capacity seemed robust with regard to both dry SAP size and $w / c$. The registered absorption capacities were almost constant within a large span of both variables, and there were no systematic trends in the observations.

The conclusions above apply to the specific type of SAP investigated herein. Future research may look into SAPs with various chemical compositions, production processes and shapes.

Further observations in this study lead to the following conclusions:

- For suspension polymerized SAP, it is suggested to rinse it before sieving it. Otherwise agglomeration caused by unremoved surfactant may influence the sieving.

- When SAP is in a narrow size range, specific surface of SAP voids obtained from measurement is in good agreement with specific surface predicted by absorption capacity and dry SAP size. This can be helpful to the application of SAP as a means of engineering void structure of cement-based materials. 


\section{Acknowledgement}

Financial support from National Key Research and Development Program of China (Grant No.

2018YFC0705404) and Natural Science Foundation of China (Grant No. 51778189) is greatly acknowledged. The authors also thank PhD student Gui Li (Technical University of Denmark) for assistance in the pretreatment of SAP and air void analyses.

\section{Compliance with ethical standards}

Conflict of Interest The authors declare that they have no conflict of interest.

\section{References}

1. Jensen OM, Hansen PF (2001) Water-entrained cement-based materials: I. Principles and theoretical background. Cem Concr Res 31(4):647-654. https://doi.org/10.1016/S0008-8846(01)00463-X

2. Jensen OM, Hansen PF (2002) Water-entrained cement-based materials: II. Experimental observations. Cem Concr Res 32(6):973-978. https://doi.org/10.1016/S0008-8846(02)00737-8

3. Mechtcherine V, Reinhardt HW (eds) (2012) Application of superabsorbent polymers (SAP) in concrete construction. State-of-the-art report prepared by Technical Committee 225-SAP, vol 2. RILEM State-ofthe-Art Reports. Springer

4. He Z, Shen A, Guo Y, Lyu Z, Li D, Qin X, Zhao M, Wang Z (2019) Cement-based materials modified with superabsorbent polymers: A review. Constr Build Mater 225:569-590.

https://doi.org/10.1016/j.conbuildmat.2019.07.139

5. Lura P, Durand F, Jensen OM (2006) Autogenous strain of cement pastes with superabsorbent polymers. In: Jensen OM, Lura P, Kovler K (eds) International RILEM conference on volume changes of hardening concrete: testing and mitigation. RILEM Publications SARL.

6. Schröfl C, Mechtcherine V, Gorges M (2012) Relation between the molecular structure and the efficiency of superabsorbent polymers (SAP) as concrete admixture to mitigate autogenous shrinkage. Cem Concr Res 42(6):865-73. https://doi.org/10.1016/j.cemconres.2012.03.011

7. Snoeck D, Jensen OM, De Belie N (2015) The influence of superabsorbent polymers on the autogenous shrinkage properties of cement pastes with supplementary cementitious materials. Cem Concr Res 74:5967. https://doi.org/10.1016/j.cemconres.2015.03.020

8. Wang F, Yang J, Hu S, Li X, Cheng H (2016) Influence of superabsorbent polymers on the surrounding cement paste. Cem Concr Res 81:112-121. https://doi.org/10.1016/j.cemconres.2015.12.004

9. Lee HX, Wong HS, Buenfeld NR (2010) Potential of superabsorbent polymer for self-sealing cracks in concrete. Adv App Ceram 109(5):296-302. https://doi.org/10.1179/174367609X459559

10. Yang H, Liu J, Zhou Q, Ji H (2019) The re-swelling behavior of superabsorbent polymers (SAPs) in hardened cement paste with an artificial crack. Mater Struct 52 (5). https://doi.org/10.1617/s11527-019$\underline{1394-1}$ 
11. Snoeck D, Van Tittelboom K, Steuperaert S, Dubruel P, De Belie N (2014) Self-healing cementitious materials by the combination of microfibres and superabsorbent polymers. J Intell Mater Syst Struct 25(1):13-24. https://doi.org/10.1177/1045389X12438623

12. Snoeck D, Dewanckele J, Cnudde V, De Belie N (2016) X-ray computed microtomography to study autogenous healing of cementitious materials promoted by superabsorbent polymers. Cem Concr Compos 65:83-93. https://doi.org/10.1016/j.cemconcomp.2015.10.016

13. Rodriguez CR, Deprez M, de Mendonca Filho FF, Van Offenwert S, Cnudde V, Schlangen E, Šavija B (2020) X-Ray Micro Tomography of Water Absorption by Superabsorbent Polymers in Mortar. In: Boshoff W, Combrinck R, Mechtcherine V, Wyrzykowski M (eds) 3rd international conference on the application of superabsorbent polymers (SAP) and other new admixtures towards smart concrete. RILEM Bookseries, vol 24. Springer, Cham. https://doi.org/10.1007/978-3-030-33342-3_4

14. Valenza JJ, Scherer GW (2007) A review of salt scaling: I. Phenomenology. Cem Concr Res 37(7):10071021. https://doi.org/10.1016/j.cemconres.2007.03.005

15. Hasholt MT, Jensen OM, Laustsen S (2015) Superabsorbent polymers as a means of improving frost resistance of concrete. Advances in Civil Engineering Materials 4(1):237-256. https://doi.org/10.1520/ACEM20150012

16. Laustsen S, Hasholt MT, Jensen OM (2015) Void structure of concrete with superabsorbent polymers and its relation to frost resistance of concrete. Mater Struct 48(1-2):357-368. https://doi.org/10.1617/s11527$\underline{013-0188-0}$

17. Kang SH, Hong SG, Moon J (2017) Absorption kinetics of superabsorbent polymers (SAP) in various cement-based solutions. Cem Concr Res 97:73-83. https://doi.org/10.1016/j.cemconcomp.2012.10.005

18. Zhao S, Jensen OM, Hasholt MT. Measuring absorption of superabsorbent polymers in cementitious environments. Mater Struct 53(1):11. https://doi.org/10.1617/s11527-020-1442-X

19. Saucier F, Pleau R, Vézina D (1996) Precision of the air void characteristics measurement by ASTM C 457: results of an interlaboratory test program. Can J Civ Eng 23(5):1118-1128. https://doi.org/10.1139/196-919

20. Elsen J (2001) Automated air void analysis on hardened concrete: Results of a European intercomparison testing program. Cem Concr Res 31(7):1027-1031. https://doi.org/10.1016/S0008-8846(01)00517-8

21. Peterson KW (2008) Automated air-void system characterization of hardened concrete: helping computers to count air-voids like people count air-voids - methods for flatbed scanner calibration (PhD thesis), Michigan Technological University.

22. Jakobsen UH, Pade C, Thaulow N, Brown D, Sahu S, Magnusson O, De Buck S, De Schutter G (2006) Automated air void analysis of hardened concrete - a round robin study, Cem Concr Res 36:1444-1452. https://doi.org/10.1016/j.cemconres.2006.03.005

23. Li G, Hasholt MT, Jensen OM (2020) Air void analysis of hardened concrete without colour enhancement. In: Kovler K, Zhutovsky S, Spatari S, Jensen OM (eds) Concrete durability and service life planning. ConcreteLife 2020. RILEM Book series, vol 26. Springer, Cham. https://doi.org/10.1007/978-3-030-43332$\underline{1 \_16}$

24. Snoeck D, Jensen OM, De Belie N (2015) The influence of superabsorbent polymers on the autogenous shrinkage properties of cement pastes with supplementary cementitious materials. Cem Concre Res 74:5967. https://doi.org/10.1016/j.cemconres.2015.03.020 
25. Krafcik MJ, Erk KA (2016) Characterization of superabsorbent poly (sodium-acrylate acrylamide) hydrogels and influence of chemical structure on internally cured mortar. Mater Struct 49(11):4765-4778. https://doi.org/10.1617/s11527-016-0823-7

26. Kang S-H, Hong S-G, Moon J (2018) Shrinkage characteristics of heat-treated ultra-high performance concrete and its mitigation using superabsorbent polymer based internal curing method. Cem Concre Compos 89:130-138. https://doi.org/10.1016/j.cemconcomp.2018.03.003

27. Almeida FCR, Rostami R, Klemm AJ (2020) The effect of SAP on volumetric changes and microstructural Alterations in PC-GGBS Matrices. In: Boshoff W, Combrinck R, Mechtcherine V, Wyrzykowski M (eds) 3rd international conference on the application of superabsorbent polymers (SAP) and other new admixtures towards smart concrete. SAP 2019. RILEM Bookseries, vol 24. Springer, Cham. https://doi.org/10.1007/978-3-030-33342-3_11

28. Liu J, Farzadnia N, Shi C (2020) Effects of superabsorbent polymer on interfacial transition zone and mechanical properties of ultra-high performance concrete. Constr Build Mater 231:117142. https://doi.org/10.1016/j.conbuildmat.2019.117142

29. Zhu Q, Barney CW, Erk KA (2015) Effect of ionic crosslinking on the swelling and mechanical response of model superabsorbent polymer hydrogels for internally cured concrete. Mater Struct 48(7):2261-2276. https://doi.org/10.1617/s11527-014-0308-5

30. Lee HXD, Wong HS, Buenfeld NR (2018) Effect of alkalinity and calcium concentration of pore solution on the swelling and ionic exchange of superabsorbent polymers in cement paste. Cem Concr Compos 88:150-164. https://doi.org/10.1016/j.cemconcomp.2018.02.005

31. Mechtcherine V, Snoeck D, Schroefl C, De Belie N, Klemm AJ, Ichimiya K, Moon J, Wyrzykowski M, Lura P, Toropovs N, Assmann A, Igarashi S, De la Varga I, Almeida FCR, Erk K, Ribeiro AB, Custodio J, Reinhardt HW, Falikman V (2018) Testing superabsorbent polymer (SAP) sorption properties prior to implementation in concrete: results of a RILEM Round-Robin Test. Mater Struct 51:28 https://doi.org/10.1617/s11527-018-1149-4

32. Kusayama S, Kuwabara H, Igarashi S (2014) Comparison of salt scaling resistance of concretes with different types of superabsorbent polymers. In: International RILEM Conference on Application of Superabsorbent Polymers and Other New Admixtures in Concrete Construction, Technische Universitat Dresden, Dresden, Germany, PRO095, pp 267-277

33. BS/EN 933-1 (2012) Tests for geometrical properties of aggregates. Part 1: Determination of particle size distribution-Sieving methods. British Standard

34. ASTM C457/C457M-16 (2016) Standard Test Method for Microscopical Determination of Parameters of the Air Void System in Hardened Concrete. American Society for Testing and Materials, West Conshohocken, Pennsylvania

35. Powers TC (1949) The air requirement of frost resistant concrete. Proceedings of the Highway Research Board 29:184-211 (also available as PCA Bulletin No. 33, Portland Cement Association, Chicago)

36. DS/EN 206:2013 (2013) Concrete - Specification, performance, production and conformity. Danish Standard

37. GB 50666-2011 (2011) Code for construction of concrete structures. Chinese Standard 
38. Assmann A (2013) Physical properties of concrete modified with superabsorbent polymers, Dr.-Ing. Thesis, University of Stuttgart

39. Esteves LP (2011) Superabsorbent polymers: On their interaction with water and pore fluid. Cem Concre Compos 33(7):717-724. https://doi.org/10.1016/j.cemconcomp.2011.04.006

40. DS/EN 206 DK NA:2019 (2019) Concrete - Specification, performance, production and conformity Rules for application of EN 206 in Denmark. Danish Standard. (in Danish)

41. ASTM C94/C94M-20 (2020) Standard Specification for Ready-Mixed Concrete. American Society for Testing and Materials, West Conshohocken, Pennsylvania 